\title{
Crisis de la ley y Estado Constitucional. La Argumentación Jurídica del Legislador. Miguel Ángel Suárez Romero. Editorial Porrúa, México, 2015, 257 páginas.
}

En la defensa del principio rector del imperio de la ley como requisito indispensable en el Estado de Derecho, el Dr. Miguel Ángel Suárez Romero en su obra "Crisis de la ley y Estado Constitucional. La Argumentación Jurídica del Legislador”, nos invita a reflexionar en torno al papel que desempeña la ley y la Ciencia de la Legislación en la comprensión del Derecho, así como la importancia que reviste una argumentación racional en terreno legislativo y jurisdiccional en el contexto del constitucionalismo contemporáneo.

La crisis de la ley, a que refiere el autor, se vincula con la redefinición y esclarecimiento del lugar de la ley en el entramado del sistema de fuentes del derecho en el marco del constitucionalismo. ${ }^{1}$ Con la finalidad de contribuir a esclarecer el lugar que ocupa la ley, el autor expone la teoría de la norma y las exigencias de racionalidad y corrección, para lo cual la argumentación jurídica en sede legislativa es un importante referente para alcanzar tales objetivos.

Bajo un marco teórico conceptual, sustentado en una profunda reflexión y comprensión del pensamiento de la filosofía política y jurídica clásica, así como de los principales representantes de la Filosofía del Derecho y Derecho Constitucional, el autor desarrolla su obra en cuatro capítulos, que se exponen a continuación:

El Capítulo Primero, intitulado la "Ley como norma y como parte del Ordenamiento Jurídico", expone los alcances de la ley, la teoría de la norma, así como del concepto de legalidad en clave constitucional, a efecto de identificar la racionalidad de la ley y determinar los alcances de la crisis de la ley.

Bajo el concepto de legalidad en clave constitucional, el autor, refiere a que la ley al depender del régimen constitucional del cual emana, conlleva a una subordinación jerárquica de la ley a la Constitución, a efecto de que el contenido de la primera sea acorde con la segunda² .

Licenciada en Derecho con Mención Honorífica por la Facultad de Derecho de la Universidad Nacional Autónoma de México. Maestra en Derecho con Mención Honorífica por la División de Estudios de Posgrado de la Facultad de Derecho de la Universidad Nacional Autónoma de México. Estudiante de Magíster Derecho Internacional: Comercio, Inversiones y Arbitraje ofrecido por las Universidad de Chile y Heidelberg.

Cfr. SuÁrez (2015), p. IX.

Cfr. Ibidem, pp. 15-16. 
Igualmente, en dicho capítulo es posible apreciar que el autor reitera su compromiso con la seguridad jurídica, ${ }^{3}$ y al efecto, a partir de la postura de F. Arcos Ramírez, Gregorio Peces-Barba y J.L. Palma Fernández, se abordan los caracteres que deben estar presentes en toda ley para que esta garantice seguridad jurídica a sus destinatarios; entre dichos caracteres destaca la claridad y precisión del texto de la norma, capacidad reguladora autosuficiente en su ámbito, seguimiento de formalidades para la promulgación de la ley, generalidad y abstracción de las disposiciones contenidas en ley, regularidad de la actuación de los poderes públicos siempre dirigidos hacia el reconocimiento y tutela de los derechos fundamentales y reserva de ley, que establece la necesidad de que ciertas materias de la convivencia social única y exclusivamente sean susceptibles de normativizarse por medio de leyes.

Otro tema que es objeto de análisis en el Capítulo Primero refiere a la ley en el contexto de la lógica del Derecho como norma y como ordenamiento, con la finalidad de determinar la estructura y composición de las disposiciones normativas y su relación con el resto de las normas que componen el Ordenamiento jurídico en su conjunto. Bajo una concepción positivista y normativa del Derecho, el autor se detiene a analizar aquellos elementos o partes que componen cada norma, centrado en las normas prescriptivas, es decir, aquellas referidas a mandatos, permisos o prohibiciones. Para tales efectos, retoma la postura de G.H. von Wright, quien destaca como elementos el carácter, el contenido, la condición de aplicación, la autoridad, el sujeto o sujetos y la ocasión, los cuales son objeto de un análisis exhaustivo en dicho capítulo.

En el estudio de la relación de la ley en el ordenamiento jurídico, el autor realiza una revisión de las propiedades que, desde un ángulo lógico, deben tener las disposiciones jurídicas en su necesaria interrelación y su pertenencia a un Sistema u Ordenamiento jurídico. En este tema adquieren especial importancia los principios lógicos que gobiernan las relaciones de las disposiciones legales en el sistema jurídico como la plenitud, coherencia e independencia, a los cuales refiere el autor bajo los postulados de autores como Rupert Schreiber, Ulrich Klug, Carlos Alchurrón y Eugenio Bulygin.

El Capítulo Primero concluye con el análisis de la posición de la ley en el Ordenamiento Jurídico. Al efecto, las fuentes del Derecho son fundamentales para comprender la posición de la ley, y en seguimiento a la perspectiva de autores como Bobbio, Guastini y Kelsen, el autor refiere que "la ley debe ser concebida como la fuente-acto del Derecho, con carácter preeminente en el orden jerárquico del sistema jurídico, que la convierte a su vez en fuente delegada y única fuente de calificación jurídica emitida por una autoridad normativa con plena capacidad y competencia, a través del acto normativo o proceso legislativo con intención de prescribir una conducta determinada, que se concreta en un texto o documento normativo que concluye la actividad reglada y que vincula a la autoridad emisora con sus destinatarios." 4

Analizado el tema de la Ley como norma y como parte del Ordenamiento Jurídico, el Segundo Capítulo refiere a la Crisis de la Ley. Al efecto, es posible identificar cinco principales motivos o causas -tanto internas como externas- que se invocan como factores importantes de la crisis de la ley. Por una parte, tendríamos aquellas externas al ordenamiento jurídico provocadoras de esta crisis, entre las

Véase SuÁrez (2009a), pp. 319-331.

SUÁREZ (2015), pp. 81-82. 
que se encuentra el resquebrajamiento de los supuestos de tipo cultural, instrumental o legitimadores de la ley en sentido moderno.

Bajo la postura normativa fijada inicialmente, el Dr. Miguel Ángel Suárez Romero centra su análisis en las causas de carácter interno que ponen en entredicho el concepto de ley. Dichas causas las ubicamos en la diversificación y competencia entre las leyes; la aparición de normas no legales, con carácter paralegal en los procesos de integración regional de los Estados; la expansión de la fuerza normativa de las constituciones y la aparición de los principios con carácter normativo.

La diversificación y competencia de leyes, en la perspectiva del autor, no representa motivo fuerte de debilitamiento del concepto de ley como fuente preeminente del sistema y ni del imperio de la ley, ya que la validez de cada una de estas disposiciones generales y abstractas que emita el Poder Legislativo se encontrará perfectamente delimitado por la norma constitucional. ${ }^{5}$

En el mismo sentido, las normas de carácter paralegal y las vinculadas con el carácter supranacional, tampoco inciden en la crisis de la ley, en tanto que son producto de las relaciones internacionales entre los Estados soberanos, que se conducen por medio de los cauces constitucionales y legales que para el efecto hayan establecido los Estados. Sobre el particular, es necesario que las disposiciones de carácter internacional estén en consonancia y no contravengan las normas constitucionales para formar parte del Derecho positivo de un Estado. En este punto, cobra importancia el criterio de unidad del Ordenamiento, en donde la propia Constitución hará compatible la aplicación y convivencia simultánea de las normas legales con otras normas provenientes de un órgano distinto al Legislativo. ${ }^{6}$

En cuanto a la expansión de la fuerza del carácter normativo de la Constitución, se argumenta que existe una crisis de la ley porque con esta normativa de la Constitución es susceptible un viraje en el que se cambie la fórmula del "imperio de la ley" por el de "imperio de la constitución". Sin embargo, para el autor, el Estado Constitucional actual, no debe ser entendido como una mera sustitución de la Constitución por la ley. Por el contrario, en este modelo debe intervenir tanto la Constitución con pleno valor y fuerza normativa, así como el propio legislador que mediante su actividad desarrolla e interpreta primariamente el texto constitucional, complementado por la ardua e importante labor hermenéutica llevada a cabo por los órganos jurisdiccionales?

En este tema, sin embargo, puede reconocerse que la ley no sea suficiente para regular todas las relaciones sociales, así como por dejar de ser el único referente de la producción normativa y en la argumentación jurídica, lo que nos conduciría a hablar de problemas relacionados con la dificultad en la aplicación por parte de los órganos encargados de dicha función, e incluso podrían aludirse a ciertos límites relativos a su eficacia, por ejemplo. Por ello, el autor advierte el interés en resolver la manera en que pueden reducirse al mínimo las insuficiencias de la ley, para lo cual la Ciencia de la Legislación es fundamental para construir la legislación en términos racionales, que a su vez se encuentre en consonancia con la propia Constitución y con el conjunto normativo que conforma el sistema ${ }^{8}$. Dicha cuestión, permite adelantar la importancia de la tarea argumentativa por parte del legislador en el Estado Constitucional actual, tema que será objeto de estudio en el Capítulo Cuarto.

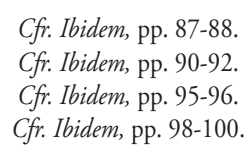


El cuarto de los factores identificado con la crisis de la ley, refiere a la aparición de los principios con carácter normativo. Sobre el particular, el autor realiza una distinción lógica y de aplicación entre reglas y principios, así como el tema de la discrecionalidad judicial, para lo cual retoma las posturas de Ronald Dworkin, Robert Alexy, Gustavo Zagrebelsky, Norberto Bobbio, H.L.A. Hart y Hans Kelsen. A partir de la diferenciación anterior, el autor destaca que la existencia de principios y reglas no debilita el concepto de ley ni el imperio de la ley, y por el contrario, la Constitución, principio y leyes requieren convivir armónicamente en el sistema jurídico y juntos sean fuente de inspiración de toda decisión jurisdiccional9 .

El Capítulo Tercero, contiene un estudio exhaustivo del Estado Constitucional de Derecho y su ubicación en la evolución del Estado de Derecho. Dicho estudio se realiza desde un modelo epistemológico del monismo jurídico, bajo el cual el Estado es el único encargado de determinar la legítima juridicidad del Derecho, y en donde la Constitución será la norma que determine la validez del resto de normas que integran el Ordenamiento jurídico.

Otro tema de interés del dicho capítulo, lo encontramos en la conexión especial entre el factor legalidad y aquel relativo a los principios democráticos y el reconocimiento de los derechos fundamentales. En este aspecto, el autor desarrolla la manera en que los derechos fundamentales consagrados en la Constitución, serán los que inspiren y a la vez limiten la actividad del legislador. Así, en el modelo de Estado Constitucional de Derecho se requiere de una tarea legislativa racionalizada y basada en los principios y valores que la norma fundamental reconoce ${ }^{10}$. A partir de lo anterior, es posible constatar que la ley desempeńa un papel relevante en la consolidación del Estado Constitucional de Derecho.

En el tema de los derechos fundamentales, el autor siguiendo el pensamiento de Gregorio Peces-Barba, retoma nuevamente la importancia que reviste la Ética Pública en el Derecho ${ }^{11}$, y así el criterio de validez de la norma no solo exige el criterio formal de pertenencia a la norma básica fundamental, sino que además es preciso contar con un criterio de validez material, representado por ese conjunto de valores y principios de carácter procedimental que son tomados de la Ética Pública, aspecto que nos permite halar de un positivismo ético o corregido, que requiere ser considerado en la comprensión del Estado Constitucional de Derecho ${ }^{12}$.

En este modelo de Estado Constitucional de Derecho, adquiere relevancia la Ciencia de la Legislación, para dar respuesta al fenómeno de la crisis de la ley, tema que será objeto de estudio en el Cuarto y último capítulo de la obra. Desde un marco teórico al cual recurre el autor para desarrollar este apartado, basado en las obras de Montesquieu, Cayetano de Filangieri, Jeremy Bentham y Manuel Atienza, el autor aborda los presupuestos de la estructura de una nueva Ciencia y Teoría de la Legislación e igualmente desarrolla los criterios de racionalidad teórica de la legislación, con la finalidad de proveer de justificación formal y material a la ley, sobre todo a partir de la referida crisis de la ley. Dichos criterios se encuentran conformados por la racionalidad lingüística, la racionalidad jurídicoformal, la racionalidad pragmática, la racionalidad teleológica y la racionalidad ética. Al efecto,

\footnotetext{
Cfr. Ibidem, pp. 101-112.

Cfr. Ibidem, pp. 137-141.

Véase Sú́REZ (2010), pp. 156-158.

Cfr. SuÁrez (2015), pp. 143-144.
} 
encontraríamos que al no cumplirse con cualquiera de dichos requisitos estaríamos ante una norma irracional en el plano argumentativo ${ }^{13}$.

Finalmente, el autor refiere a la Teoría de la Legislación en términos de la racionalidad práctica, la cual tiene a la argumentación jurídica como una de sus especies, y que representa el terreno donde se llevaría a cabo la discusión y consenso en materia legislativa. La aproximación metodológica empleada en este tema parte de una argumentación jurídica en lo general para después concretar la argumentación en la producción y establecimiento de normas ${ }^{14}$, basada en ciertos cánones argumentativos, que determinen la racionalidad de la decisión y al mismo tiempo su validez para poder pertenecer plenamente al Ordenamiento jurídico ${ }^{15}$, con lo cual el autor presenta una propuesta epistemológica para hacer frente a las causas y postulados que afirman una crisis de la ley, para lo cual la racionalidad legislativa es fundamental para defender el imperio de la ley en el Estado Constitucional de Derecho.

Por lo anterior, la obra "Crisis de la Ley y Estado Constitucional de Derecho" del Dr. Miguel Ángel Suárez Romero, es de gran utilidad para los juristas a fin de desarrollar nuevas líneas de investigación en torno al rol que la ley desempeńa en la actualidad, así como la argumentación jurídica en sede legislativa. Asimismo, los postulados de la obra invitan a asumir con seriedad la importancia del proceso legislativo en el fortalecimiento del Estado Constitucional de Derecho. Ciertamente ante el fenómeno de la globalización y creciente dinámica y participación de nuevos actores en los sectores público, privado y social, es indispensable contar con leyes apegadas a criterios de racionalidad que brinden seguridad y certeza jurídica a las actividades que realicen dichos actores.

\section{Referencias Bibliográficas}

Suárez Romero, Miguel Ángel y Conde Gaxiola, Napoléon (2009b): Argumentación Jurídica. Cuadernos de Trabajo, Universidad Nacional Autónoma de México, México, 78 pp.

SuÁrez Romero, Miguel Ángel (2009a): "La seguridad jurídica a la luz del ordenamiento jurídico mexicano", en: Revista de la Facultad de Derecho de México, número 252, pp. 311-332.

SuÁrez Romero, Miguel Ángel (2010): "Humanismo y Ética en los Derechos Fundamentales. Una propuesta de reafirmación”, en: Revista de la Facultad de Derecho de México, número especial, pp. 153-160.

SuÁrez Romero, Miguel Ángel (2013): "Estado Constitucional y Argumentación Jurídica en sede Legislativa”, en: Derechos y Libertades, número 28, Época II, pp. 139-167.

SuÁrez Romero, Miguel Ángel (2015): Crisis de la ley y Estado Constitucional. La Argumentación Jurídica del Legislador, Porrúa, México, 257 pp.

\footnotetext{
Véase SuÁrez (2009b), pp. 54-55.

Cfr. SUÁREZ (2015), pp. 220-221.

Véase Sú́rez (2013), pp. 157-163
} 